\title{
The Informal Caregivers' Viewpoint About Care Inhibitors for Community-Dwelling Elderly in an Iranian Context: A Qualitative Study
}

\author{
Samaneh Pourhadi', Hamid Reza Khankeh², Reza Fadayevatan', Robab Sahaf ${ }^{1 *}$ \\ 1. Iranian Research Center on Ageing, Department of Ageing, University of Social Welfare and Rehabilitation Sciences, Tehran, Iran. \\ 2. Department of Nursing, University of Social Welfare and Rehabilitation Sciences, Tehran, Iran.
}

Citation: Pourhadi S, Khankeh HR, Fadayevatan R, Sahaf R. The Informal Caregivers' Viewpoint About Care Inhibitors for Community-Dwelling Elderly in an Iranian Context: A Qualitative Study. Iranian Rehabilitation Journal. 2016; 14(3):185-196. https://doi.org/10.18869/nrip.irj.14.3.185

d oi : : https://doi.org/10.18869/nrip.irj.14.3.185

\section{Article info:}

Received: 24 Apr. 2016

Accepted: 01 Sep. 2016

\section{Keywords:}

Inhibitors, Care, Communitydwelling elderly, Informal caregiver

\section{ABSTRACT}

Objectives: Following the rise in the elderly population worldwide and the increase in chronic diseases among this demographic with their consequent need for care, the subject of elderly care is becoming increasingly important. Considering the traditional standing of the elderly in Iranian society and the importance of in-community care for them, it seems of crucial importance to study the obstacles hindering the care for community-dwelling elderly for a better understanding of the status. This can also facilitate the conditions for the care-givers and care-receivers on the part of policy makers and managers.

Methods: In this study, using purposive sampling, 19 semi-structured in-depth interviews were conducted with informal care-givers and were then transcribed verbatim. The content analysis of the transcribed interviews was carried out by determining conceptual units, precise coding, and constant comparative method. Then, the sub-categories and main categories were gradually formed.

Results: Data analysis was carried out in constant mode simultaneous with the data collection. From the whole set of interviews, 311 preliminary codes were extracted. The codes were obtained throughout the process of analysis in three main categories of personal, family, and social factors. All categories had their own subcategories that were integrated into certain categories based on their own specific characteristics. The subcategories included the characteristics of the caregiver and the elderly, the lack of knowledge and awareness about caregiving, the lack of support and cooperation on the part of the family members, financial problems, unsuitable homes, the lack of government support, and obstacles hindering the presence of the elderly in the society.

Discussion: The inhibitors affect a proper caregiving and based on their own nature, cause discomfort to the caregiver and care receiver. Many of these cases are deemed as rectifiable hindrances that can lead us to optimal care for community-dwelling elderly if the cases are taken into consideration and proper strategies are designed and implemented in small and large scale planning.

\section{* Corresponding Author:}

Robab Sahaf, PhD

Address: Iranian Research Center on Ageing, Department of Ageing, University of Social Welfare and Rehabilitation Sciences, Tehran, Iran.

Tel: +98 (21) 22180077

E-mail: robabsahaf@gmail.com 


\section{Introduction}

$\mathbf{P}$

opulation aging is a far-reaching problem in both the developed and developing countries [1]; however, this phenomenon is relatively new worldwide [2]. In Iran, various factors have contributed to the issue of population aging; some of these factors are increased birth rate, advances in medicine, healthcare, and education, and the increase in life expectancy [3].

Although old age and disease are two entirely different processes, the risk of many physical and mental illnesses and death increases with old age, and this adds to the fact that the mere passage of time and an unhealthy lifestyle cause diseases [2]. Old age can be defined with respect to biological, sociological, psychological, and chronological perspectives $[2,4,5]$. By taking into consideration the differences in life expectancies among different countries and communities, the World Health Organization (WHO) has considered the age of 60 years as the borderline at which old age commences [6]. This is also valid for Iran [7].

The aging process can increase the number of dependencies, i.e. the individual's need for social, family, and institutional support due to temporary or complete loss of their abilities [10], and the need for long-term cares. Moreover, chronic diseases limit the number of daily activities and increase the demand for elderly cares and services $[8,9]$. The aging of the population is a natural phenomenon and cannot be stopped or reversed, but the impacts of this process can be controlled using proper policies [3]. Therefore, given the aging of the society and the importance of taking care of the elderly individual, it is crucial to pay special attention to the discourse of caring for community-dwelling elderly.

Since population aging is a relatively new phenomenon in Iran, there is no comprehensive and coherent plan in this regard and lack of certain services. In particular, there is no written documentable evidence among scientific resources. The policies regarding elderly care in Iran seem to be based on taking care of the elderly persons in the society, and this issue has been emphasized in this study.

Although it has no global definition, caring includes different facets such as the level of physical and tools-assisted performance, medical conditions, the number and frequency of the activities that require assistance from the caregiver, emotional and affective dependency, and the comprehension and interpretation of the ecology of caring on the part of both the caregiver and care receiver [10]. However, there is still a gap between the different definitions of care, its method of implementation, and its outcomes [11]

The ongoing decrease in death rates, as well as the rise in the life expectancy, has contributed to a rapid and everincreasing growth of the elderly population. The Iranian society and family, especially in big cities, are undergoing extensive changes $[3,12]$. The changes in the family and the trend of urbanization and industrialization have threatened the social standing of the elderly who previously enjoyed a special status inside families. Presently, this situation has degraded to the extent that families cannot afford to give sufficient care to the elderly [3]. Studies show that cultural norms and differences should be considered when designing care services because these services are provided for somebody who possesses a distinguished set of beliefs, virtues, and lifestyle [13]. Thus, it seems that the elderly care in the Iranian context may have different aspects and definitions that are tailored to the social, cultural, and economic conditions in this country, and it is important to consider these differences to provide better care for the elderly.

However, there are different hindrances in society, with respect to the social, economic, and cultural status of that society and its individuals, that pose a challenge for elderly care plans $[13,14]$. Therefore, the present study aims to identify the obstacles hindering the implementation of care plans for community-dwelling elderly.

Many studies in the field of elderly care have been conducted from a qualitative perspective [15-17], but most of these studies are limited to a specific group of elderly and caregivers $[18,19]$. Some studies are limited to a certain group of family caregivers and care receivers [10]. Other groups of studies have focused on elderly with special problems (with dementia) [20-23] and have examined them from the perspective of family caregivers. A number of studies have also dealt with the attitude towards caregiving and the impacts of elderly caring on the family [24]. Also, some studies have solely focused on the caregiving load [20] or the social and economic issues with caring [25].

Furthermore, since there are a variety of elderly caregiving services in developed countries, most of such studies have dealt only with a certain aspect in each of these caring environments [26-29]. One study has extracted the benefits, obstacles, and facilitators of the elderly residing in nursing homes using formal and informal caregivers as participants [30]. The present study has investigated the caring process at nursing homes, but the status of the caring process with community-dwelling elderly needs more research. 
Due to the delay on the part of the society in confronting with the aging issue and limited related services compared to that of the societies pioneering in this field, relevant research in this field is limited in Iran. The majority of the studies have been conducted quantitatively and were focused on remedial and healthcare aspects with a medical and nursing approach merely assaying, comparing, and analyzing the relations among certain variables within the scope of old age.

Various studies have compared between communitydwelling elderly and the ones at nursing homes based on different perspectives [31-33]. Some studies investigated the attributes of caring and caregivers with respect to the elderly suffering from Alzheimer's disease and residing at nursing homes [34]. Some others have focused on identifying the problems [35], pressure [36, 37], and health issues [38] faced by caregivers when caring for the elderly with Alzheimer's disease. Another group of studies has investigated the social problems faced by the caregiving families [39] or have dealt with the implementation and evaluation of a caregiving model [40].

Most of the qualitative studies have focused on the vantage point of informal caregivers with respect to a certain group of the elderly (e.g. vulnerable subjects) [18] or they have been limited to a certain group of caregivers, namely women taking care or vulnerable elderlies [41]. According to resources, only $7 \%$ of the communitydwelling elderly are vulnerable [2]. So, in the present study, we have tried to identify the factors inhibiting the caregiving process to community-dwelling elderly from the vantage point of family caregivers.

\section{Methods}

Due to the insufficiency of quantitative methods in measuring certain human phenomena [41], this study has used the qualitative method to describe the experiences in the lives of caregivers. The conventional content analysis has been used to analyze the data and identify the factors that hinder giving care to Iranian elderly dwelling in the community. This method of analysis enables the researcher to extract the category labels from the data by immersing in them and consequently forming a thorough insight about them [42].

This method is focused on the life experiences, the interpretations, and concepts the participants declare [43]. Constant comparative analysis leads to a conceptual classification, which aims to develop the categories based on their characteristics and dimensions via con- tent analysis, a process which is called open coding in grounded theory [44].

According to this method, the content of the analysis is read several times to identify, extract, and code the conceptual units. Based on the continuity of the induction and interpretation of the content, and according to the code similarities, the categories, subcategories, and their relations are extracted [42].

Qualitative study makes use of individuals' experiences from the social process being studied. The sampling was first done in a purposeful manner and was then continued theoretically according to the conditions until the data saturation was achieved. The participants in this study were informal caregivers engaged in caring for community-dwelling elderly. They were information-rich cases, aware of the question being studied, and had recently experienced the topic under study $[45,46]$. Cooperating well and the ability to convey their experiences to others are also among the criteria for choosing the right participants. Data saturation means "the completion of all code levels when there is no more conceptual data to be rendered into new codes or no possibility to expand the incumbent codes any further".

The common attribute in this type of sampling was the commitment to observing and interviewing the individuals who have experienced the phenomenon under study $[45,47]$. The targeted person among informal caregivers (family member, relative, and friend) was the one who spent time taking care of the elderly more than the rest and was the one responsible for the cares. Furthermore, having the willingness and preparedness to participate in the study has been a requirement. Elderly here meant women and men aged 60 years or above and who needed others' help in at least one of their activities of daily living (ADL). The absence of cognitive impairment and a recent case of acute or limiting illness was also considered within the inclusion criteria.

The data was collected through deep semi-structured interview, observation of interactions, and journaling $[45,47]$. The interviews were conducted based on guide structured by the researcher and the esteemed supervisors. Two pilot interviews were also conducted so that guide could be revised accordingly. The interviews began with the exchange of personal information, getting to know more about each other, introducing the objective of the study, and obtaining the official written consent of the participant. Such sessions continued with general and open questions such as, "please tell me about your experiences with the elderly (father, mother, friend, 
neighbor, care receiver)", or "what problems or limitations are you facing when giving care?"

Then, the questions gradually focused on the caregiver's comprehension and conceptual elucidation of experience from elderly care. Whenever needed, questions such as "like what", "what does that mean", "please explain", and "please give an example" were asked. The order of questions changed as the data collection progressed, and each interview proceeded as per the answers of the participants and the main questions of the study. The goal was to arrive at a single and similar understanding of the phenomenon under study as experienced by the interviewee. All interviews were recorded, and after each interview, the complete text along with the emotions of the participant such as tone of speaking, silence, and laughs were transcribed and coded. The interviews were typically of 45 to 60 minutes [48].

In this study, the researcher has tried to observe the actions and interactions among the elderly and informal caregivers by taking into consideration the verbal and nonverbal behavior and has focused on the space, the objects in the area, sequence of actions, and the interactions of the individuals. If possible, the notes were taken simultaneously along with the observation, but in cases where it was not possible, the observer would record her observation as soon as she got the chance [49].

In addition, memos and field notes were written during data collection so as to include all important points. The researcher would decide which data to collect early on and which to collect later. Therefore, it was the concepts that were being followed, and the study progressively focused on a certain topic that was of importance to the development of the idea, the participant, and the researcher. This meant that the researcher formed her own presuppositions so that she could later analyze and test them after the completion of data collection [50].

The manuscripts from the researcher's observations during her presence in the study environment were also used as a useful source for data collection. In other words, the researcher would record the event according to what happened in the environment, assign a code to it, and then put it next to other codes for subcategory extraction. The researcher would also write down her own impressions and then compare them with the obtained concepts.

In a qualitative study, the environment is the real-time and genuine field of the phenomenon where the very people of interest reside and their experiences happen at that very place or any place the participant chooses [51].
In this study, the interviews were mostly held at the caregiver's and the elderly's home, so that, in addition to the interview itself, it was also possible to observe the caregiving process, conditions, and space. Other items were dealt with at the workplace or any other place picked by the participants (e.g. a park or a coffee shop). A total of 19 interviews were conducted; the first interview was with a married woman taking care of her old mother. She was proposed by the study team.

Each interview was completely transcribed into MS Word, and the data were analyzed using the conventional content analysis. The data collection and the analysis process were carried out in parallel and were alternated with each other. In other words, after the completion of each interview, the data were transcribed and analyzed. In fact, there was an interaction between the data collection and the data analysis at each stage.

The interview scripts were read repeatedly to determine the conceptual units as words, sentences, and paragraphs. Then, a suitable name was assigned to each conceptual unit based on the terms (in Vivo Codes) used by the participants or determined by the researcher. In this way, the codes were extracted and classified into categories and subcategories based on the observations and conceptual connections. In general, the following eight stages were considered in the analysis [42]:

- Data preparation;

- Conceptual units determination;

- Coding of the text;

- Controlling and coordinating the codes with the text;

- Grouping and expanding the categories based on their similarities and consistencies;

- Reviewing the categories and re-comparing them with the data to ensure the robustness of the codes;

- Precise determination of the main categories and further comparison among them; and

- Reporting the findings.

To ensure the precision and trustworthiness of the data during the roughly 1-year study, the researcher was totally engaged in the acquisition of information, with constant connection with the participants. Most of the times, she worked toward a deeper perception and understanding of the information. A triangulation of the information source, data collection method, and the researcher was also incorporated. To triangulate the method, besides the 
semi-structured interview, observations, field notes, and memos were also used.

The emphasis was on picking participants with the most possible variety in socioeconomic status and level of education. The method of reviewing by the participants and experts in the field of elderly affairs was also incorporated. The interview and the relevant codes, and the order of categories and subcategories were studied by the guiding and advising instructors. The scripts and codes from the interviews were handed out to those participants who expressed their willingness to go over them.

The tendency was to describe all stages including data collection, analysis, and the extraction of codes and categories in such that other scholars would be able to make judgments by reading them, that is, the findings of the study are properly supported by the data collected. The stages of the study were described as comprehensively as possible so that the work could be easily audited by others, and the quality of the integrated process of data collection and analysis and the theory presentation could be conveniently evaluated. It should be noted that the researcher has done her best to accurately convey the participants' views in the study.

To observe the code of ethics, the researcher has tried to be considerate of the following points: the goals of the study were clearly and completely elucidated for the participants, and after their agreement, their signatures were elicited under the consent form. The time and place of interview were determined with the participants' preference, agreement, and consent. The interviews were recorded with the participants' consent, and the aim and method of using the recorded conversation was elucidated for them. They were guaranteed that their personal information would remain confidential, and they were permitted to withdraw from the process at any time during the study. Also, the official ethical permission was received from the Ethics Committee of the University of Social Welfare and Rehabilitation Sciences.

\section{Results}

In the present study, 19 family care-givers with the most significant role in elderly care were included. The participants consisted of 14 women and 5 men; of them, 11 were married, 5 were single, 1 was a widow, and 2 were divorced. The participants' ages ranged between 28 years and 74 years, with the lowest and highest education being illiterate and specialized doctoral, respectively. Of the total participants, 15 were related to the elderly as children ( 9 daughters taking care of their mothers, 2 daughters taking care of their fathers, 2 sons taking care of their fathers, and 2 sons taking care of their mothers), 1 as the spouse, 2 as daughters-in-law (1 taking care of her father-in-law and the other taking care of her motherin-law), and 1 as son-in-law (taking care of his motherin-law). The participants had been in charge of care for the elderly of the family for at least 1 year. After reading through the interviews and isolating the conceptual units, a total of 311 codes were extracted out of the study and were classified under three subcategories based on topic similarity and constant comparison. The caregivers' experiences showed that certain factors act as inhibitors in the process of caregiving causing hardships and problems, which will be explained in detail later.

\section{The $1^{\text {st }}$ main category: Individual factors}

The findings of the study indicate that personal circumstances and problems are important causes that limit the ability of the family in caregiving. This category consists of items that either intentionally or unintentionally create obstacles for elderly care.

\section{Characteristics of the caregiver and the elderly}

It refers to a set of features of the caregiver and the elderly that affect the caregiving process. These characteristics can be age, physical and mental health status, employment, the level of business, patience, and the level of the elderly's disability and dependence.

About her old father-in-law's impatience and intolerance, a daughter-in-law said, "things that he asks, if not delivered on time, not on time, but rather according to his own will, no matter what the thing, say he asks for water now or names a food, he really wants it right then and there, kind of very restless and impatient" (A married woman, 68-old-age).

A daughter informed about her old mother's increasing intolerance, "Well, recently she gets a little frustrated, when she calls and if you get there late she'll shout, you know, getting intolerant" (A widow, 61-year-old).

Moreover, many participants spoke of their jobs and the time spent on them that causes interference between the caregiving tasks and those of their occupation, leading to additional problems. A daughter said in this regard, "the long time I spend outside at work hinders giving care to my mother more than anything else. Well, I leave her alone for 10 hours every day and obviously when I come back I'm quite tired"' (A single woman, 33-year-old). 
Lack of knowledge and awareness about caregiving

Our findings showed that the lack of sufficient knowledge and awareness about elderly care contributes to the difficulty of proper decision-making and planning to deal with the elderly issues in the family. In this regard, a participant said, "sometimes, we have to get involved in caregiving without being prepared for such a task, without any prior conception of the issue and all. Now in all these obligations, unpreparedness, without prior arrangements, with no background in the job, no mental preparedness, readiness, preparations, well it's quite possible the person will stumble here and there, sometimes they don't know how to do something, sometimes they do the job but not in the correct way; with all that I do I still feel there were things I could have done but I didn't, especially things that weren't deliberate, maybe I was then so preoccupied with other stuff, maybe it didn't cross my mind at all, maybe I needed somebody to tell me, maybe I needed to be reminded about that certain stuff or I needed training..." (A single woman, 46-year-old).

Another caregiver reiterated, "we didn't have much information in terms of how to give care. We did whatever we thought was right, but I think it could have been done more structured" (A divorced man, 74-year-old).

\section{The $2^{\text {nd }}$ main category: Family factors}

Family factors have been identified as one of the most important categories extracted in this study that has had a major share in limiting the caregiving process. The participants' experiences in this study show that the family setting has limited the conditions for caregiving so much so that the care givers are grappled with much difficulty in doing their caregiving tasks. The related themes are lack of support and cooperation on the part of family members, and the family's financial problems.

\section{Lack of support and cooperation from family} members

Lack of sharing chores among family members led to irresponsibility and inadequate support towards caring for the elderly. Lack of timely backup and substitute work force added to the caregiving workload. A participant said, "There are times when a job comes up out of the blue and I may get stressed out about say I'm handling this task and I need to call somebody too. I wish I always had somebody available to assist me to get such things done" (A single woman, 42-year-old).

Another participant said, "Well he (The caregiver's brother) did not show up even once, all these months she was lying in the hospital, all these more than five years he's never stopped by, he doesn't care at all” (A married man, 69-year-old).

Dissatisfaction on the part of some family members is also evident. In this regard, a participant said, "once or twice, we had to be there from morning till night, each day one of us stayed there, it was quite hard for us, and after some time the husbands of our younger sisters started to complain" (A married woman, 54-year-old).

\section{Financial problems}

Some caregivers asserted that they could not afford the costs of caregiving at home. For example, the household income or pension could not meet the high costs of health and care services provided for the elderly at home, and they regretted that they were not able to do much for their elderly or they had to sacrifice their own or their family's needs for the elderly care. On this subject, a participant said, “...because my mom receives pension, she has to manage her living costs after all, but you know that these retirement benefits are so inadequate" (A married woman, 65-year-old).

Another participant added, "why does an office worker have to pay his pension to keep his mother, what's his fault, what has he got?" (A married man,69-year-old).

\section{Unfit homes}

A number of participants brought up the issue of unfit homes and lack of proper home facilities for elderly care, apartment living and the consequent room limitations, lack of elevators or living space specially modified to fit the elderly commute. A participant said, "Even getting those mattresses mom or dad sleep on. You know, some furniture has to be replaced to fit them. Their home has got some amenities that aren't safe enough. Of course there are flush toilet, grab bars and stuff, but they are worn out, they have to be replaced, and we don't have them." (A married woman, 44-year-old)

"For example, when we want to take her out, and since she needs to climb down the stairs on wheelchair, and there's no elevator, we have to carry her down on the wheelchair, it's a bit difficult for us really, there needs to be two men to bring her down" (A married woman, 54-year-old).

\section{The $3^{\text {rd }}$ main category: Social factors}

Our findings showed that a major portion of obstacles on the way of elderly care in families arise from social inadequacies and shortcomings. The burden and pres- 
sure from caring is so much that caregivers feel the need to receive more social support.

\section{Lack of government support}

A number of participants in this study deemed the present governmental and social support to caregivers as unsatisfactory, and they had demands from organizations and institutions. The participants' experiences showed that the services rendered on the part of relevant organizations had been so poor that could not play a considerable role in alleviating the families' problems. For example, they named the lack of financial and mental-emotional support to the elderly or the absence of an insurance tailored for the elderly. On the lack of social support for community-dwelling elderly, a participant said, "Whenever the children could, they would visit them, mentally, emotionally, visiting, taking them to the doctor, but when they don't, who will make these right, or their medication too. There are sometimes children who are married, have left for other cities for education, what will come to these elderly?" (A married woman, 44-year-old).

"when there's no insurance, if she had been insured since youth, that would have been the right insurance, the house keeper would be insured, but it's not so now, you tell me, what percent of this country is insured, only office workers, what about others, are they insured? What about the self-employed? How can he afford the costs?" (A married man, 69).

Obstacles on the way of the elderly's presence in the society

Some caregivers referred to things that keep the elderly from being present in the society, resulting in the feeling of loneliness and lack of variety for their free time. These groups of items include problems with the transportation system, physical problems in the society, and moral and cultural problems. On this subject, a participant said, "with this age, my father cannot go anywhere by bus or taxi, it's hard to take him around town. If he needs to go somewhere, well, sometimes somebody passes away or there is a friends gathering, he can't always sit at home so that maybe others will come and see him, it's depressing" (A single man, 28-year-old).

"For example, my mother in law likes eating out very much, she loves going out in general, but first we have to investigate if the place doesn't have many stairs or if it has a flush toilet so that we can take her" (A married woman, 46-year-old).

"Going to the park is good for her spirits, but it's so hard for us to take her, she needs to go to the toilet so often. Before you get there she has to be taken somewhere, there don't exist the facilities" (A married woman, 65-year-old).

Observing moral codes and privacy for the presence and participation of the elderly in the society is inevitable. About this aspect, a participant said, "Sometimes somebody might just be kidding saying wow look at that oldie, he's aged so well, and it's very disheartening for the elderly that hears it" (A single woman, 46-year-old).

"For example, my father says I feel so ashamed when I'm outside, sometimes people feel pity when they see me, hello, why have you become like this! He says people stare at me or ask questions" (A married woman, 43-year-old).

\section{Discussion}

Based on this study, the three categories of individual, familial, and social factors have been identified as the barriers to providing care by family caregivers for community-dwelling elderly. As caregivers take on the caregiving role, they face with these obstacles and consequently suffer hardships. In this study, we have tried to use caregivers with various relations including child, daughter-in-law, son-in-law and spouse taking care of the male and female elderly. Since most elderly in need of care receive the care from their children, the spouse has had the least engagement compared to other relatives.

From among the individual factors, the lower the physical and mental health level of the caregiver and the elderly, the harder the process of caring. Also, the poorer the knowledge and awareness of the caregiver about caregiving, the more problems and hardships s/he had to endure, hence, having to devise solutions based on what was available. Despite the fact that the lower age of the caregiver was synonymous with better physical health, s/ he had a busier life.

Also, older caregivers who were less busy were apparently a better candidate for caregiving due to the fact that they were retired and their children had already married, but they themselves were having their own problem of poor health. Furthermore, the elderly at higher ages had more disabilities.

A qualitative study by Kramer in 1997 on old husbands suffering from Alzheimer's disease reported that the personal characteristics of the caregiver and elderly influenced the quality of family care and the caring load experienced through the caring process [52]. Mohammadi et al showed in a qualitative study on female caregivers 
that working women, particularly the ones facing time shortage due to different chores, experienced a harder caregiving process [41]. Results from other studies [53, 54] also showed that insufficient knowledge and information on the part of families added to the load experienced by the caregiver, and individuals did not know what decision to make when faced with such difficulties. This, in turn, would lead to a lower threshold of tolerance to the resulting pressures.

It is advisable to train the family members under a structured curriculum to raise the caregivers' level of knowledge, awareness, and skills required for an effective caregiving, so that people would not have to choose the best practice at each point through trial and error. Of course, there is no single prescription to advise all, and everybody needs to plan based on the existing circumstances, facilities, and abilities that are unique to them, but training the family members in general basics can be very useful. The trainings may even need to begin early at daycare centers and primary schools. Smith believes that nurses can inspire caregiving and efficiency spirits in caregivers by training the family in elderly care methods and providing them with consultations.

Additionally, nurses can alleviate the negative consequences of caring by controlling the side effects of the pressure on caregiving [55]. A study on the effects of training and consulting programs on the general health of women giving care to the elderly with Alzheimer's disease revealed that the families are in need of effective training methods to help improve the health of people giving care to the elderly [56]. In another study that dealt with the effects of family training programs on the load of caring for elderly with dementia, the load was shown to reduce right after the intervention. Therefore, it can be very helpful to design and assess the implementation of such projects [57].

The caregiver's health, the elderly's behavioral and cognitive impairment, the image that the elderly has of his own situation, the load, pressure, and stress experienced by the caregiver [58], the caregiver's job and social activities, shortage of time, the elderly's age of over 75 years [10], the aspects from which the elderly is dependent on the caregiver, and the caregiver's age and physical situation are among the effective factors in the caregiving process [11].

Based on the findings from this study, families suffering from the lack of support and cooperation from other family members, financial problems, and physically unfit homes, tended to have less patience and tolerance towards the existing conditions.
In their study, Pouladi et al. showed that families would not leave any stone unturned to strike a balance between needs and responses, and to that end, they certainly faced problems such as insufficient income and physical limitations of the home. Also, the unavailability of other relatives and their lack of feeling of responsibility towards the elderly resulted in the caregivers' need being left unmet [53]. Sarmah and Choudhury also found that the industrialization of today's society has caused conflicts in the family roles among the present generation [59].

In a study about safe and ergonomic homes for the elderly in Malaysia, Norazizan et al. concluded that improving the quality and satisfaction of the elderly according to the person-environment fit theory is attainable using proper handles, non-slippery floorings, grab bars in bathrooms, toilets, halls, rooms, and on stairs, flattening any elevated surfaces on the floor, and raising independence in the elderly's personal life [60].

Our findings show that the lack of government support and the existence of numerous obstacles in the way of elderly's social presence deprive them from a lot of activities. For example, families and the elderly face different limitations when choosing spare time activities.

Access to resources and the presence of a variety of formal and informal support in the society affects the elderly care [61]. In the social status quo, informal caregivers, because of their jobs and the fact that they are playing multiple roles simultaneously, feel more in need of support and formal and informal help [62].

Caregiving workload increases the need for formal support. Pouladi says that the budget problems on the part of the organizations supporting families and elderly has disabled the capacity to provide formal support for caregiving families [53]. Also, Mohammadi et al. have emphasized the inefficiency of organizational formal support to families giving care to the elderly, and the families' need for additional insurance for the elderly, and allocating governmental facilities for the caregivers who care for the elderly at homes [41].

According to a report by the Iranian Central Bank, the Iranian health system like other health systems is facing the harsh challenge of cost increase. While the overall index of costs in the country has increased 30 -fold during the last 20 years, the health sector costs have had a 71-fold increase [63]. This fact has caused a lot of problems in different sectors for the health system. So, the increasing costs of healthcare, the rising expectations of the public, and limitations in the resources and payments show the presence of 
an economic challenge in the country's health system that has particularly overshadowed the families [53].

Bookman and Kimbrel's study on the role of governmental support in relieving the family's economic challenges when caring for the elderly shows the effectiveness of governmental organizations in taking on responsibilities for supporting the elderly in the United States. While in the United States, the family is the first to take care of the elderly, a major portion of elderly care responsibilities are still regarded to be that of governmental organizations. Some of these centers are responsible for financial and health supports for the elderly, and some others are in charge of giving social support to the family [64].

In their study on the experiences of the elderly and caregivers from within the family about whether the city of Tabriz is elder-friendly, Sadeghi et al. emphasized on the need for the standardization of city transportation, reduction of taxi fares, securing of the sewage system, fighting vermin, trainings via the media, installing signs that are specifically designed for the elderly, installing benches along the streets and neighborhoods, standardization of parks, and providing security [65]. Nemati and Aghabakhshi also stated that the city needs modifications to be at par with the elderly-friendly cities; some of these modifications include building proper bridges and underpasses, and isolating some spaces in parks where there is the risk of cyclists and skaters bumping into senior citizens. Furthermore, the sitting areas, public restrooms, and the safety and hygiene of the routes and parks need to be revised [66].

\section{Conclusion}

The families provide care and long-term services to the elderly in Iran at home. Considering the upward trend in the population of the elderly and sustained tendency among Iranian families and elderly to nurse the elderly at home, it is crucial to identify the existing obstacles and tackle them optimally. The individual, familial, and social obstacles encompassing the caregiver's and the elderly's characteristics, lack of knowledge and awareness about caregiving, lack of support and cooperation from family members, financial problems, unfit homes, lack of government support, and obstacles in the way of the elderly's presence in the society, have been influential in providing care for the elderly.

These obstacles reveal a weak health system infrastructure and an insufficient and unsatisfactory application of the existing potentials to support the families who provide care for their elderly. It is necessary to pay attention to the limitations identified in this study, i.e. researches are needed to identify the existing potentials and suggest practical solutions in this area so that any mistreatment of the elderly or their transfer to nursing homes would be prevented. This way, we would also be able to identify the incumbent needs and prepare plans in micro- and macro-scale based on these potentials to implement the best solutions to boost the family health system infrastructure. Doubtlessly, it would be impossible to succeed in health system without identifying and meeting the demands and expectations of the society.

\section{Acknowledgements}

I would like to thank the Ageing Department of the University of Social Welfare and Rehabilitation Sciences for their cooperation. I would also like to express my gratitude for the contributions made by the esteemed participants. The present study is extracted from the $\mathrm{PhD}$ thesis of Samaneh Pourhadi, Department of Ageing, University of Social Welfare and Rehabilitation Sciences, Tehran.

\section{Conflict of Interest}

The authors declared no conflict of interests.

\section{References}

[1] World Health Organization. Health care of elderly in Eastern Mediterranean region: Challenges and perspectives. Geneva: World Health Organization; 2003.

[2] Halter JB, Ouslander JG, Tinetti ME, Studenski S, High KP, Asthanan S. Hazzard's Geriartic Medicine \& Gerontology. $6^{\text {th }}$ ed. New York: McGraw-Hill Companies, Inc.; 2009.

[3] Gheysarian E. [Examining social and economic dimensions of elderly phenomenon in Iran (Persian)]. Quarterly of Population. 2009; (69-70):1-28.

[4] World Health Organization. 10 facts on ageing and the life course. Geneva: World Health Organization; 2012.

[5] Seyed-Mirzaei SM. [Some observations on the dimensions of aging with a look at Japan's experience (Persian)]. Journal of Human Sciences. 2007; 53:201-22.

[6] Mirfallah Nassiri SN. [Demographic determinants of population ageing and related indicators in Iran (Persian)]. Iranian Journal of Official Statistics Studies. 2008; 18(2):1-14

[7] Mirzaei M, Shams Ghahfarrokhi M. [Demography of Iranian elderly based on census 1956-2006 (Persian)]. Iranian Journal of Ageing. 2007; 2(3):326-31.

[8] Alizadeh M, Khoshbin S, Khavarpour F. [Assessing quality of life, well being and depression among the Iranian elderly residents of Australia (Persian)]. Iranian Journal of Ageing. 2009; 4(4):15-26. 
[9] Connell PJ. A phenomenological study of the lived experiences of adult caregiving daughters and their elderly mothers. [PhD dissertation] Florida: University of Florida; 2003.

[10] Connell PJ. A phenomenological study of the lived experiences of adult caregiving daughters and their elderly mothers. Florida: University of Florida; 2003.

[11] Finch LP. Development of a substantive theory of nurse caring. International Journal for Human Caring. 2008; 12(1):25-32

[12] Sheikhi MT. [Social security and pathology of the elderly in Tehran: Sociological study (Persian)]. Iranian Journal of Ageing. 2008; 2(4):454-61.

[13] Maddah SB. [The status of social and leisure time activities among elderly residing in Iran and Sweden (Persian)]. Iranian Journal of Ageing. 2009; 3(8):597-606.

[14] Abedi HA, Alavi M. [The experiences of health care team and elderly in-patients about concept of "elderly patients' education" in a hospital affiliated to Isfahan University of Medical Sciences (Persian)]. Iranian Journal of Medical Education. 2007; 7(1):93-100.

[15] Shaibu S, Wallhagen MI. Family caregiving of the elderly in Botswana: Boundaries of culturally acceptable options and resources. Journal of Cross-Cultural Gerontology. 2002; 17(2):139-54. doi: 10.1023/a:1015886307661

[16] Boland DL, Sims SL. Family care giving at home as a solitary journey. Journal of Nursing Scholarship. 1996; 28(1):5558. doi: 10.1111/j.1547-5069.1996.tb01179.x

[17] Gates K. The experience of caring for a loved one: A phenomenological study. Nursing Science Quarterly. 2000; 13(1):54-9. doi: 10.1177/08943180022107285

[18] Chao S, Roth P. The experiences of Taiwanese women caring for parents-in-law. Journal of Advanced Nursing. 2000; 31(3):631-38. doi: 10.1046/j.1365-2648.2000.01319.x

[19] Limpanichkul Y, Magilvy K. Managing caregiving at home: Thai caregivers living in the United States. Journal of Cultural Diversity. 2004; 11(1):18-24. PMID: 15357223

[20] Miyamoto Y, Tachimori H, Ito H. Formal caregiver burden in dementia: impact of behavioral and psychological symptoms of dementia and activities of daily living. Geriatric Nursing. 2010; 31(4):246-53. doi: 10.1016/j.gerinurse.2010.01.002

[21] Butcher H, Holkup P, Buckwalter K. The experience of caring for a family member with Alzheimer's disease Western Journal of Nursing Research. 2001; 23(1):33-55. doi: $10.1177 / 01939450122044943$

[22] Subgranon R, Lund DA. [Maintaining Caregiving at Home: A Culturally Sensitive Grounded Theory of Providing Care in Thailand. Journal of Transcultural Nursing. 2000; 11(3):16673. doi: $10.1177 / 104365960001100302$

[23] Shyu Y, Archbold P, Imle M. Finding a balance point: a process central to understanding family caregiving in Taiwanese families. Research in Nursing \& Health. 1998; 21(3):261-70. doi 10.1002/(sici)1098-240x(199806)21:3<261::aid-nur9>3.0.co;2-f

[24] Abdulraheem I. An opinion survey of caregivers concerning caring for the elderly in Ilorin metropolis, Nigeria. Public Health. 2005; 119(12):1138-144. doi: 10.1016/j. puhe.2005.04.005
[25] Okoye U, Asa S. Caregiving and Stress: Experience of People Taking Care of Elderly Relations in South-eastern Nigeria. Arts \& Social Sciences Journal. 2011:1-9.

[26] Muntinga ME, Hoogendijk EO, van Leeuwen KM, van Hout HP, Twisk JW, van der Horst HE, et al. Implementing the chronic care model for frail older adults in the Netherlands: study protocol of ACT (frail older adults: care in transition). BMC Geriatrics. 12:19. doi: 10.1186/1471-2318-12-19

[27] Jerant AF, Azari RS, Nesbitt TS, Meyers FJ. The TLC model of palliative care in the elderly: preliminary application in the assisted living setting. Annals of Family Medicine. 2004; 2(1):54-60. doi: 10.1370/afm.29

[28] Chun R. Long term care services for the elderly. Minnesota: Minnesota House of Representatives; 2007.

[29] Wild D, Nelson S, Kydd A, Szczepura A. Implementing a care model for the older person. Nursing Times. 2012; 108(31):26-29. doi: 10.7748/nop.28.4.26.s22

[30] Stewart F, Goddard C, Schiff R, Hall S. Advanced care planning in care homes for older people: A qualitative study of the views of care staff and families. Age \& Ageing. 2011; 40(3):330. doi: 10.1093/ageing/afr006

[31] Hesamzadeh A, Shahbolaghi FM, Falahi Khoshknab M, Rahgozar M. [Comparison of elderlys" quality of life" living at homes and in private or public nursing homes (Persian)]. Iranian Journal of Ageing. 2010; 4(4):66-74.

[32] Momeni K, Karimi H. [Comparison of mental health between elderly admitted in sanitarium with elderly in sited in personal home (Persian)]. Journal of Kermanshah University of Medical Sciences. 2010; 14(4):328-35.

[33] Mokhtari F, Ghasemi N. [Comparison of quality of life and mental health of elderly residents/non-residents of nursing homes (Persian)]. Iranian Journal of Ageing. 2010; 5(18):53-63.

[34] Yekta Talab S, Kaveh M, Sharif F, Khoshknab MF, Pedramfar P. [Characteristics of care and caregivers of alzheimer patients in elder care homes: A qualitative research (Persian)]. Iranian Red Crescent Medical Journal. 2012; 14(5):1-6.

[35] Zohari S, Khatoni S, Saeedi ZA, Alavi Majd H, Yaghmaie F. [Problems of main caregivers of alzheimer patients referring to Alzheimer Association in Tehran (Persian)]. Journal of Nursing and Midwifery. 2006; 53:66-76.

[36] Mohammadi F, Babaee M. [The effect of participation in "family support groups of Iran Alzheimer. Association" on the caregiving strain and spiritual wellbeing among family caregivers of elders with Alzheimer (Persian)]. Iranian Journal of Ageing. 2011; 6(19):29-37.

[37] Mohammadi Shahbolaghi F. [Study of caregivers self efficacy and caregiving strain among family caregivers of patients with Alzheimer (Persian)]. Iranian Journal of Ageing. 2006; 1(1):26-33.

[38] Bastani F, Hosseini R, Bani Asad MM, Haghani H. [Gerneral health of caregiver women of elderly with Alzheimer's disease (Persian)]. Iranian Journal of Ageing. 2010; 5(17):43-51.

[39] Babaei M. [Social problems of families caring for a frail elderly referrals to public hospitals clinics in Karaj city (Persian)]. Iranian Journal of Ageing. 2007; 2(3):177-81. 
[40] Norouzi K, Abedi HA, Maddah S, Mohammadi E, Babaei G. Development of a community-based care system model for senior citizens in Tehran. Iranian Rehabilitation Journal. 2005; 3(3):48-60.

[41] Mohammadi F, Dabbaghi F, Yadavar-Nikravesh M. [Facilitating and hindering factors in Iranian female family caregivers experiences (Persian)]. Iranian Journal of Ageing. 2007; 2(6):445-53.

[42] Hsieh H, Shannon S. Three approaches to qualitative content analysis. Qualitative Health Research. 2005; 15(9):127788. doi: $10.1177 / 1049732305276687$

[43] Pope C, Royen PV, Baker R. Qualitative methods in research on healthcare quality. Quality \& Safety in Health Care 2002; 11(2):148-52. doi: 10.1136/qhc.11.2.148

[44] Corbin J, Strauss A. Basics of qualitative research: Techniques and procedures for developing grounded theory. Philadelphia: Sage Publications, Inc.; 2008.

[45] Adib Haj Bagheri M, Parvizi S, Salsali M. [Qualitative research methods (Persian)]. Tehran: Boshra Publication; 2011.

[46] Zohoor AR, Moonaghi HK. [Data analysis in qualitative studies (Persian)]. Quarterly Journal of Fundamentals of Mental Health. 2003; 20:107-13.

[47] Oskoui SF, Peyrovi H. [Qualitative research in nursing (Persian)]. Tehran: Iran University of Medical Sciences; 2005.

[48] Sanei AS, Nasrabadi AN. [Qualitative research methods in medical sciences (Persian)]. Tehran: Baraye Farda Pulication; 2004.

[49] Grove S, Burns N, Gray J. The practice of nursing research appraisal, synthesis, and generation of evidence. $7^{\text {th }}$ ed. China: Elsevier; 2013.

[50] Gerrish K, Lacey A. The research process in nursing. $6^{\text {th }}$ ed. Singapore: Blackwell Publishing, Ltd.; 2010.

[51] Streubert H, Carpenter D. Qualitative research in vursing: Advancing the humanistic imperative. $4^{\text {th }}$ ed. Philadelphia: Lippincott Williams \& Wilkins; 2007.

[52] Kramer B. Gain in the caregiving experience: Where are we? What next? Gerontologist. 1997; 37(2):218-32. doi: 10.1093/geront/37.2.218

[53] Pouladi S, Anoosheh M, Kazemnejad A, Zareiyan A. [Factors limiting families in elderly care: A thematic analysis (Persian)]. Journal of Research in Health Sciences. 2013; 2(2):14657.

[54] Mohammadi F, Kaldi A. Self-efficacy and caregiver strain in Alzheimer's caregivers in the City of Tehran. Middle East Journal of Age \& Ageing. 2006; 3(3):8-12.

[55] Kasper JD, Steinbach U, Andrews J. Factors associated with ending caregiving among informal caregivers to the functionally and cognitively impaired elderly population. Baltimore: Johns Hopkins University; 1990.

[56] Hosseiny R, Bastani F, Sayahi S, Momen-Abadi H, Alijanpoor-Aghamaleki M. [The effect of education consulting program on general health of women as caregivers of patient, with Alzheimer disease (Persian)]. Journal of Shahr-e Kord University of Medical Sciences 2011; 13(5):83-92.
[57] Pahlavanzadeh S, Heidari FG, Maghsudi J, Ghazavi Z, Samandari $S$. The effects of family education program on the caregiver burden of families of elderly with dementia disorders. Iran Journal of Nursing and Midwifery Research. 2010; 15(3):102-08. PMCID: PMC3093163

[58] Salarvand S, Abedi HA, Shamloo K. Experiencing powerlessness sense in elderly residents of nursing home. Iran Journal of Nursing. 2007; 20(50):1-10.

[59] Sarmah C, Choudhury B. Problems of elderly and their care. Journal of Human Ecology. 2011; 36(2):145-51.

[60] Norazizan S, Dadgari A, Ahmad N, Dadvar L. [Safety and ergonomics in home bourd elderly adults: an application of person environment fit theory in Malaysia (Persian)]. Knowledge \& Health Journal. 2008; 2(4):48-54. doi: 10.1234/jkh. v2i4.281.g402

[61] Pinquart M, Sorenson S. Gender differences in caregiver stressors, social resources, and health: An updated meta-analysis. Journals of Gerontology Series B; Psychological Sciences \& Social Sciences. 2006; 1(61):33-45. PMID: 16399940

[62] Mohammadi F, Dabbaghi F, Yadavar Nikravesh M. [Facilitator and barrier factors in family caregiving process of Iranian frail elderly: A qualitative study (Persian)]. Iran Journal of Nursing. 2009; 55(13):55-65.

[63] Davari M. [Economic challenges of health system in Iran (Persian)]. Management of Health Information. 2010; 8(7):91517.

[64] Bookman A, Kimbrel D. Families and elder care in the twenty-first century. Future of Children. 2011; 21(2):117-40. doi: $10.1353 /$ foc. 2011.0018

[65] Sadeghi F, Kaldi A, Sahaf R. [Explore the experiences of the elderly and their family caregivers of being elder friendly of Tabriz (Persian)]. Iranian Journal of Ageing. 2011; 6(23):41-51.

[66] Nemati D, Aghabakhshi H. [Tehran, an elder-friendly city, the first steps to realize the first elderly capital in the world (Persian)]. Journal of Social Research. 2013; 6:15-44. 
